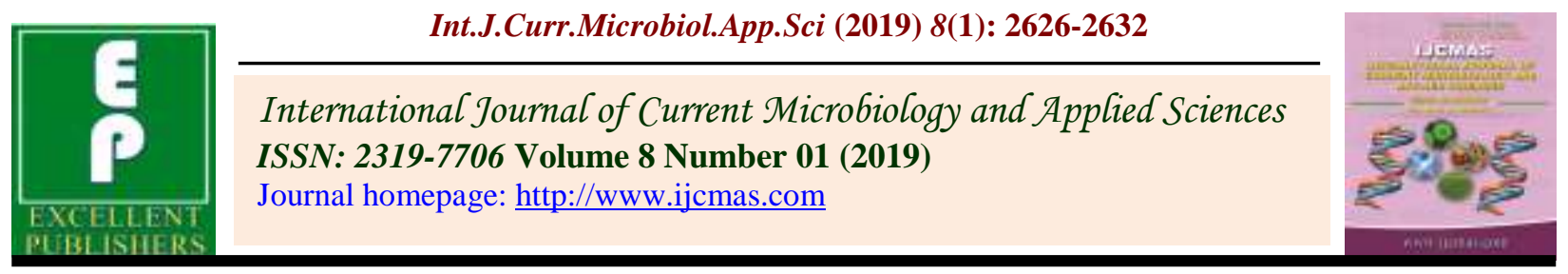

Original Research Article

https://doi.org/10.20546/ijcmas.2019.801.276

\title{
Derivation of the Intensity-Duration-Frequency Curve for Annual Maxima Rainfall using Generalised Extreme Value Distribution
}

\author{
M.R. Namitha ${ }^{1^{*}}$ and V. Vinothkumar ${ }^{2}$ \\ ${ }^{1}$ Department of Agriculture Engineering, Sethu Institute of Technology, \\ Anna University, India \\ ${ }^{2}$ Department of Farm Machinery and Power, Tamil Nadu Agricultural University, India \\ *Corresponding author
}

\section{A B S T R A C T}

Keywords

Generalised

Extreme Value

distribution, Chi-

square test,

Empirical

Reduction Formula,

Rainfall Intensity

Duration Frequency

Curves

Article Info

Accepted:

17 December 2018

Available Online:

10 January 2019
The analysis of one-day maximum rainfall for 27-years rainfall data in Kumulur region was conducted using Gumbel distribution and Generalized Extreme Value distributions. The parameters of the distributions were estimated using the method of L- moments. Annual one-day maximum rainfall data for 27-years was analyzed and the return levels for 2, 5, 10 and 25-years were calculated using the proposed probability distribution functions. The goodness of fit of the probability distribution was analysed by conducting Chi-square test. It was found that, the annual maxima rainfall data for one day maximum rainfall of Kumulur region fits best with the Generalized Extreme Value distribution. The short duration rainfall depths for 1-hr, 2-hr, 3-hr, 5-hr, and 8-hr were calculated using the Empirical Reduction Formula proposed by the Indian Meteorological Department. The intensity of the obtained rainfall depths was also calculated. The rainfall IntensityDuration-Frequency (R-IDF) curves were plotted for the region and the corresponding empirical equations were derived.

\section{Introduction}

Intensity, duration and frequency are identified as the principle characteristics of a rainfall, which influences the planning design, operation and maintenance of soil and water conservation structures. The relationship between rainfall Intensity-DurationFrequency trio is an important tool for the proper implementation of different water resources technology projects. Rainfall intensity-duration-frequency (IDF) curves are graphical representations of the amount of water that falls within a given period of time in catchment areas (Dupont et al. 2006). Rainfall intensity is expressed as the rate of rainfall in millimetres per hour (Okonkwo and Mbajiorgu, 2008). Duration represents the total time period during which the storm occurs. Frequency is how often a storm of specified intensity and duration may be expected to occur (Rick, 2007). 
Unexpected extreme rainfall events result in flooding hazards worldwide. Various probability distributions can be used to predict the design rainfall fairly accurately for certain return periods, even though the nature of rainfall is erratic and varies with time and space (Upadhaya and Singh, 1998). According to Smith (1993), the rainfall frequency analysis problem is to compute the amount of rainfall falling over a given area in duration of $\mathrm{x}$ minutes with a given probability of occurrence in any given year. However, a safe and economic design of small dams, bridges, culverts, irrigation and drainage work etc. can be well planned by the analysis of annual maxima rainfall.

Many researchers have pointed out the importance of analysis of rainfall intensityduration-frequency curves for design of hydrologic structures. Design engineers and hydrologists require one day maximum rainfall at different return periods for appropriate planning and design of small and medium hydraulic structures like small dams, bridges, culverts, etc. (Aggarwal et al., 1988).

This study figures out the variation in intensity-duration-frequency relationship for one day maxima rainfall for the proposed return periods, using Generalized Extreme Value distribution.

\section{Materials and Methods}

AEC \& RI, Kumulur campus, having 10.55'29.34" N latitude and 78.49'35.61'E longitude, located in Lalgudy taluk in Trichy district of Tamilnadu is chosen as the study area. The average annual rainfall of the area was found to be $85.8 \mathrm{~cm}$.

The daily rainfall data for past 27 years (1991-2017) was collected from the meteorological observatory in AEC \& RI, Kumulur campus. The annual maximum rainfall for one day was calculated for the 27 years (1991-2017) data (Table 1).

The statistical parameters of annual 1-day maximum rainfall are shown in Table 2. Gumbel distribution and Generalized Extreme Value distribution were used for the analysis of extreme rainfall events and the calculation of return periods.

\section{Fitting the distributions for the extreme rainfall analysis}

\section{Generalized Extreme Value distribution (GEV)}

The GEV distribution is a family of continuous probability distributions that combines the Gumbel (EV1), Fréchet and Weibull distributions. GEV makes use of 3 parameters: location, scale and shape.

The CDF of GEV is defined in (Hosking, 1997) as:

$\boldsymbol{F}(\boldsymbol{x})=\exp \left\{-\left(1-\frac{k(\mathrm{x}-\xi)}{\alpha}\right)^{\frac{1}{k}}\right\}$

where, $\xi$ is the location parameter, $\alpha$ is the scale parameter, and $\kappa$ is the shape parameter.

\section{Gumbel distribution (EV1)}

Gumbel distribution, also referred as Extreme Value Type-1 distribution is used for the study of extreme hydrologic events (e.g. extreme rainfall, peak flow etc.) The EV1 distribution uses only 2 parameters, location $(\xi)$ and scale $(\alpha)$.

The CDF for Gumbel distribution as defined in (Hosking, 1997) is:

$\mathbf{F}(\mathrm{x})=\exp \left[-\exp \left(-\frac{x-\xi}{\alpha}\right)\right]$ 
where, $\xi$ is the location parameter, $\alpha$ is the scale parameter.

\section{Parameter estimation for the distributions}

The parameter estimation of the probability distribution was done by using the method of L-moments by applying the equations proposed by Cunnane (1989) (Table 3).

\section{Return periods and return levels}

Return period ( $\mathrm{T}$ ) also known as a recurrence interval (sometimes repeat interval) is an average length of time in years for an event (e.g. flood or river level) of given magnitude to be equalled or exceeded at least once (Table 4). The return period for an event can be calculated by the following formula:

$T=\frac{N+1}{m}$

where, $\mathrm{N}$ is the total number of years of record and $\mathrm{R}$ is the rank of observed rainfall values arranged in descending order. Return levels represents the amount of rainfall equalled or exceeded at the given return period. In this study, the return levels of rainfall are calculated for the assumed return periods of 2, 5, 10 and 25 years.

\section{Calculation of return levels}

The return levels for the corresponding return periods are calculated using Gumbel (EV1) and Generalised Extreme Value distribution.

\section{Generalised extreme value distribution}

The return value is defined as a value that is expected to be equalled or exceeded on average once every interval of time $(\mathrm{T})$ (with a probability of $1 / \mathrm{T}$ ). Therefore, $\mathrm{CDF}$ of the GEV distribution [i.e., equation (1)] $=1-1 / \mathrm{T}$, which implies:
$X_{T}=\xi+\frac{\alpha}{k}\left[1-\left(-\ln \left(1-\frac{1}{T}\right)\right)^{k}\right]$

where, $\mathrm{T}$ is the return period, $X_{T}$ is the return level at $\mathrm{T}$ years.

\section{Gumbel distribution}

The equation for fitting the Gumbel distribution to observed series of flood flows at different return periods $\mathrm{T}$ is (Sarma, 1999):

$X_{T}=\bar{X}+K \sigma$

where, ${ }^{X_{T}}$ denotes the magnitude of the $\mathrm{T}$ year flood event, $\mathrm{K}$ is the frequency factor $\bar{X}$ and $\sigma$ are the mean and the standard deviation of the maximum instantaneous flows respectively.

The frequency factor expresses as:

$$
K=-\frac{\sqrt{6}}{\pi}\left(0.5772+\ln \left(\ln \frac{T}{T-1}\right)\right)
$$

The table 5 shows the observed and calculated return levels using the proposed probability distribution functions.

\section{Goodness of fit}

The goodness of fit between the observed and the expected return levels were analysed using Chi-square test.

$x^{2}=\sum_{i=1}^{n} \frac{\left(O_{i}-E_{i}\right)^{2}}{E_{\bar{i}}}$

where, ${ }^{O_{i}}$ is the observed rainfall and ${ }^{E_{i}}$ is the expected return level using probability distribution functions.

\section{Estimation of short duration rainfall}

The empirical reduction formula (eq. 16) proposed by Indian Meteorological 
Department (IMD) was used for finding the short duration rainfall values at various durations like 1-hr, 2-hr, 3-hr, 5-hr, 8-hr.

$\boldsymbol{P}_{t}=\boldsymbol{P}_{24} \sqrt[3]{\frac{t}{24}}$

where, $P_{t}$ is the required rainfall depth in $\mathrm{mm}$ at $\mathrm{t}$-hr duration, $\mathrm{P}_{24}$ is the daily rainfall in $\mathrm{mm}$ and $t$ is the duration of rainfall for which the rainfall depth is required in hour.

The rainfall intensity for a particular short duration rainfall can be calculated by the following formula

$I_{t}=\frac{P_{t}}{t}$

where, $I_{t}$ is the intensity of rainfall in $\mathrm{mm} \mathrm{h}^{-1}$ for return period $T, P_{t}$ is the required rainfall depth in $\mathrm{mm}$ at $\mathrm{t}$-hr duration and $\mathrm{t}$ is the duration in hours.

\section{Results and Discussion}

The return levels of extreme rainfall for one day were calculated using the cumulative distribution functions of both Gumbel and Generalised Extreme Value distributions. Chisquare test was conducted for comparison of the results with observed data. The expected return levels using generalised extreme value distribution was found to have a good agreement with the observed data, since a minimum chi-square value is Generalised Extreme Value distribution than that of Gumbel distribution.

Table.1 Annual maximum rainfall for one day

\begin{tabular}{|l|l|c|}
\hline Sl. No. & Year & Annual maximum rainfall for one day \\
\hline $\mathbf{1}$ & 1991 & 151 \\
\hline $\mathbf{2}$ & 1992 & 85.1 \\
\hline $\mathbf{3}$ & 1993 & 106.2 \\
\hline $\mathbf{4}$ & 1994 & 71.8 \\
\hline $\mathbf{5}$ & 1995 & 100 \\
\hline $\mathbf{6}$ & 1996 & 122.6 \\
\hline $\mathbf{7}$ & 1997 & 69.7 \\
\hline $\mathbf{8}$ & 1998 & 120 \\
\hline $\mathbf{9}$ & 1999 & 205.8 \\
\hline $\mathbf{1 0}$ & 2000 & 90.5 \\
\hline $\mathbf{1 1}$ & 2001 & 84 \\
\hline $\mathbf{1 2}$ & 2002 & 156.6 \\
\hline $\mathbf{1 3}$ & 2003 & 57.6 \\
\hline $\mathbf{1 4}$ & 2004 & 115.8 \\
\hline $\mathbf{1 5}$ & 2005 & 115.2 \\
\hline $\mathbf{1 6}$ & 2006 & 69.9 \\
\hline $\mathbf{1 7}$ & 2007 & 158 \\
\hline $\mathbf{1 8}$ & 2008 & 149 \\
\hline $\mathbf{1 9}$ & 2009 & 176 \\
\hline $\mathbf{2 0}$ & 2010 & 136.6 \\
\hline $\mathbf{2 1}$ & 2011 & 78.5 \\
\hline $\mathbf{2 2}$ & 2012 & 94.4 \\
\hline $\mathbf{2 3}$ & 2013 & 80 \\
\hline $\mathbf{2 4}$ & 2014 & 67 \\
\hline $\mathbf{2 5}$ & 2015 & 61.4 \\
\hline $\mathbf{2 6}$ & 2016 & 58.6 \\
\hline $\mathbf{2 7}$ & 2017 & 110 \\
\hline & & \\
\hline
\end{tabular}


Table.2 Statistical parameters for annual one day maximum rainfall

\begin{tabular}{|l|l|c|}
\hline \multicolumn{1}{|c|}{ Sl. No. } & \multicolumn{1}{|c|}{ Parameters } & Value \\
\hline 1. & Minimum $(\mathrm{mm})$ & 57.6 \\
\hline 2. & Maximum $(\mathrm{mm})$ & 205.8 \\
\hline 3. & Mean $(\mathrm{mm})$ & 108.90 \\
\hline 4. & Standard deviation, $\sigma(\mathrm{mm})$ & 7.93 \\
\hline 5. & Coefficient of skewness & 0.74 \\
\hline 6. & Kurtosis & -0.18 \\
\hline
\end{tabular}

Table.3 Parameters for the probability distribution functions

\begin{tabular}{|r|l|c|c|}
\hline Sl. No. & \multicolumn{1}{|c|}{$\begin{array}{c}\text { Parameters for the } \\
\text { Probability distribution }\end{array}$} & GEV & Gumbel \\
\hline $\mathbf{1}$ & Scale, $\alpha$ & 31.69 & 32.59 \\
\hline $\mathbf{2}$ & Location, $\xi$ & 89.66 & 90.09 \\
\hline $\mathbf{3}$ & Shape, $\mathrm{k}$ & -0.0297 & - \\
\hline
\end{tabular}

Table.4 Observed and Expected return levels for one day maximum rainfall

\begin{tabular}{|l|l|c|l|l|}
\hline S. No. & $\begin{array}{l}\text { Return } \\
\text { Period }\end{array}$ & $\begin{array}{r}\text { Observed rainfall for one } \\
\text { day maximum rainfall }\end{array}$ & \multicolumn{2}{|c|}{$\begin{array}{l}\text { Expected return level for one day } \\
\text { maximum rainfall }\end{array}$} \\
\cline { 3 - 5 } & & & Gumbel & GEV \\
\hline $\mathbf{1}$ & 2 & 100 & 107.59 & 101.3382 \\
\hline $\mathbf{2}$ & 5 & 149 & 114.61 & 138.2678 \\
\hline $\mathbf{3}$ & 10 & 158 & 119.25 & 163.4113 \\
\hline $\mathbf{4}$ & 25 & 205.8 & 125.12 & 195.9922 \\
\hline
\end{tabular}

Table.5 Rainfall IDF empirical relations using GEV

\begin{tabular}{|c|c|c|}
\hline Sl. No. & Return period & Equation \\
\hline $\mathbf{1}$ & 2 & $y=341.6 e^{-0.008 x}$ \\
\hline $\mathbf{2}$ & 5 & $y=465.9 e^{-0.003 x}$ \\
\hline $\mathbf{3}$ & 10 & $y=550.6 e^{-0.008 x}$ \\
\hline $\mathbf{4}$ & 25 & $y=660.4 e^{-0.003 x}$ \\
\hline
\end{tabular}


Fig.1 Rainfall IDF curves obtained using GEV distribution

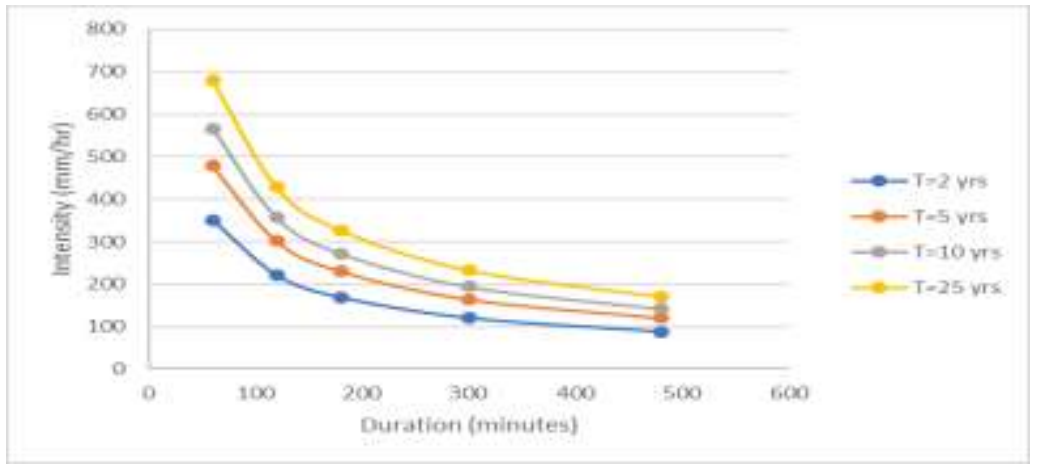

The short duration rainfall depths were calculated for 1-hr, 2-hr, 3-hr, 5-hr and 8-hr durations using the empirical formula proposed by the Indian Meteorological Department (IMD). The intensity of rainfall was calculated by using eq. 9 . The calculated intensity for the proposed durations for $2-\mathrm{yr}$, 5-yr, 10-yr and 25-yr return periods were plotted and depicted in figure 1 .

The R-IDF curves clearly depict an inverse exponential relationship between intensity and duration. The intensity found to be increasing with the increase in return periods. The empirical formulas derived for the R-IDF curves were tabulated in table 5 . The result of regression analysis derived a best correlation between the two parameters giving an $\mathrm{R}^{2}$ value of 0.914 .

In conclusion, the 27-year rainfall data of the study area was analysed statistically using two types of probability distribution functions. The GEV distribution was found to fit best with the data, giving a least chi-square value. The short duration rainfall for 1-hr, 2hr, 3-hr, 5-hr and 8-hr was derived using Empirical Reduction Formula proposed by Indian Meteorological Department. The duration of rainfall, corresponding intensity for the proposed return levels were plotted and the results were analysed. The R-IDF empirical relations were obtained using regression analysis.

\section{References}

Aggarwal MC, Katiyar VS, Ram Babu (1988). Probability analysis of annual maximum daily rainfall of UP Himalayan. Indian J Soil Cons 16(1): $35-42$.

Bhattacharya, A. K., and T. K. Sarkar. (1982). Analysis of Rainfall Data for Agricultural Land Drainage Design. Journal of Agricultural Engineering, 19(1):15-25.

Cunnane, C. (1989). Statistical distributions for flood frequency analysis. WMO Operational Hydrology Report no. 33. World Meteorological Organization, Geneva, Switzerland. Pp. 49-95.

Dupont, B.S., Allen, D.L. (2006). "Establishment of Intensity- Duration - Frequency Curves for Precipitation in the Monsoon Area of Vietnam" Kentucky Transportation Center, College of Engineer, University of Kentucky in corporation with US Department of Transportation.

Hosking, J.K.M. and Wallis, J.R. (1997). Regional frequency analysis, an approach based on \&moments, Cambridge university press.

Okonkwo, G.I. (2008). Rainfall IntensityDuration-Frequency Analysis for South Eastern Nigeria. Unpublished M.Eng Project Report, Department of Agric and Bioresources Engineering, 
University of Nigeria, Nsukka. pp 95.

Rick, K. (2007). Statistics of Weather and Climate Extremes. http://www.isse.ucar.edu/Hp_rick/

Sarma, P. 1999. Flood risk zone mapping of Dikrong sub basin in Assam.

Smith, James A. (1993). "Precipitation" in
Handbook of Hydrology, edited by David R. Maidment. New York: McGraw-Hill, Inc.

Upadhaya A, Singh SR (1998) Estimation of consecutive days maximum rainfall by various methods and their comparison. Indian J Soil Conser., 26(2):193-201.

\section{How to cite this article:}

Namitha, M.R. and Vinothkumar, V. 2019. Derivation of the Intensity-Duration-Frequency Curve for Annual Maxima Rainfall using Generalised Extreme Value Distribution. Int.J.Curr.Microbiol.App.Sci. 8(01): 2626-2632. doi: https://doi.org/10.20546/ijcmas.2019.801.276 